\title{
Glyceraldehyde-3-phosphate dehydrogenase of Edwardsiella tarda has protective antigenicity against Vibrio anguillarum in Japanese flounder
}

\author{
Ying Liu' ${ }^{1}$, Syun-ichirou Oshima ${ }^{2, *}$, Kenji Kawai $^{1}$
}

\begin{abstract}
${ }^{1}$ Fish Disease Laboratory, Department of Aquaculture, Faculty of Agriculture, and ${ }^{2}$ Laboratory of Cell Structure and Function, Division of Marine Bioresource Science, Graduate School of Kuroshio Science, Kochi University, Nankoku, Kochi 783-8502, Japan
\end{abstract}

\begin{abstract}
Edwardsiella tarda glyceraldehyde-3-phosphate dehydrogenase (GAPDH) may be an effective vaccine candidate against infection by E. tarda in Japanese flounder Paralichthys olivaceus. The GAPDH of E. tarda is highly homologous to that of Vibrio cholerae (91\%), and therefore E. tarda GAPDH may have protective antigenicity against Vibrio species. In this study, we immunized Japanese flounder with GAPDH of $E$. tarda and infected the fish with $V$. anguillarum. The result showed that GAPDH prepared from E. tarda protected Japanese flounder effectively in a challenge of $V$. anguillarum. Therefore, E. tarda GAPDH should be considered as a multi-purpose vaccine candidate against several kinds of pathogenic bacteria.
\end{abstract}

KEY WORDS: Glyceraldehyde-3-phosphate dehydrogenase - GAPDH · Protective antigenicity · Multi-purpose vaccine candidate $\cdot$ Edwardsiella tarda $\cdot$ Vibrio anguillarum

\section{INTRODUCTION}

A $37 \mathrm{kDa}$ outer membrane protein (OMP) among different serotype strains of Edwardsiella tarda is effective against infections by different serotype strains of E. tarda (Kawai et al. 2004). N-terminal amino acid sequence analysis showed that the $37 \mathrm{kDa}$ OMP is homologous to glyceraldehyde-3-phosphate dehydrogenase (GAPDH), a cytoplasmic enzyme common in organisms (Kawai et al. 2004). To develop E. tarda GAPDH as a vaccine against $E$. tarda, Liu et al. (2005) obtained a sequence of the gene encoding $E$. tarda GAPDH, overexpressed the GAPDH protein, and evaluated the vaccine efficacy of expressed GAPDH against $E$. tarda infection. The GAPDH of both nucleotide and amino acid sequences are highly similar between E. tarda and other Gram-negative bacteria, and have especially high homologies between E. tarda and Vibrio cholerae (Liu et al. 2005).

Vibrio sp. are the etiological agents of severe diarrheal diseases in fish and humans and cause epidemic diarrheal diseases that are feared because of their severity (Kusuda \& Salati 1993, Kaper et al. 1995). The high similarities of GAPDH between Edwardsiella tarda and $V$. cholerae prompted us to examine the protective antigenicity of E. tarda GAPDH against Vibrio infection.

\section{MATERIALS AND METHODS}

Bacterial strains and culture conditions. The Edwardsiella tarda EF-1 strain was cultured as described in Kawai et al. (2004). Vibrio anguillarum strain 1122 (J-O-3) isolated from ayu Plecoglossus altivelis was pre-cultured in brain heart infusion (BHI, Difco) broth containing $2 \% \mathrm{NaCl}$ at $25^{\circ} \mathrm{C}$ for $1 \mathrm{~d}$, inoculated into new $\mathrm{BHI}$ broth containing $2 \% \mathrm{NaCl}$, and then cultured at $25^{\circ} \mathrm{C}$ for $18 \mathrm{~h}$.

Antigen. The $37 \mathrm{kDa}$ OMP of Edwardsiella tarda EF-1 strain was extracted as described (Suzuki et al. 1994). The antigen underwent sodium dodecyl sul- 
Table 1. Preliminary experiment to determine adequate bacterial (Vibrio anguillarum) dose for challenge test

\begin{tabular}{|lccc|}
\hline $\begin{array}{l}\text { Dose of } V . \\
\text { anguillarum } \\
\left(\mathrm{CFU} \text { fish }^{-1}\right)\end{array}$ & $\begin{array}{c}\text { Number } \\
\text { of fish }\end{array}$ & $\begin{array}{c}\text { Mean body } \\
\text { weight } \\
(\mathrm{g})\end{array}$ & $\begin{array}{c}\text { Mortality rate } \\
\text { after 2 wk } \\
(\%)\end{array}$ \\
\hline $8 \times 10^{6}$ & 30 & 21 & 97.6 \\
$4 \times 10^{6}$ & 30 & 21 & 70 \\
$2 \times 10^{6}$ & 30 & 21 & 10 \\
$8 \times 10^{5}$ & 30 & 21 & 0 \\
$4 \times 10^{5}$ & 30 & 21 & 0 \\
\hline
\end{tabular}

phate polyacrylamide gel electrophoresis (SDS-PAGE) and was visualized by Coomassie brilliant blue staining. The prepared protein also underwent Western blotting by using antiserum against the E. tarda $37 \mathrm{kDa}$ OMP (Kawai et al. 2004) and antiserum against general (human, rabbit, and Escherichia coli) GAPDH (Biogenesis), respectively.

Fish and immunization. Japanese flounder Paralichthys olivaceus weighing about $21 \mathrm{~g}$ were obtained from a hatchery in Kochi Prefecture, Japan, and were divided into 2 groups: Group $1(\mathrm{n}=50)$ was immunized with the $37 \mathrm{kDa}$ GAPDH prepared from Edwardsiella tarda $\left(30 \mu \mathrm{g}\right.$ fish $\left.^{-1}\right)$ by intraperitoneal injection, and Group 2 ( $\mathrm{n}=50$ ) was intraperitoneally injected with phosphate-buffered saline (PBS; $100 \mu \mathrm{l}$ fish $^{-1}$ ) as a control. The fish were reared in aquaria for $4 \mathrm{wk}$ and were infected with Vibrio anguillarum strain 1122.

Challenge test. The appropriate dose of Vibrio anguillarum for a challenge test was determined in a preliminary infection experiment. A broth culture of $V$. anguillarum strain 1122 was diluted to 5 different concentrations. Thirty Japanese flounder were intraperitoneally injected with each of the 5 diluted bacterial suspensions (Table 1). The number of injected $V$. anguillarum was counted on agar plates after serial dilutions.

Based on the results of this preliminary experiment, the immunized fish in the 2 groups were challenged by a dose of $4.0 \times 10^{6}$ colony-forming units (CFU) fish ${ }^{-1}$ with intraperitoneal injection. Mortality was recorded twice a day for $2 \mathrm{wk}$. Significant differences between the 2 groups were calculated by Fisher's exact test.

\section{RESULTS}

Fig. 1A shows a single band at the $37 \mathrm{kDa}$ site (Lane 1), suggesting that the $37 \mathrm{kDa}$ OMP was successfully separated from other OMPs. Fig. 1B shows that the protein reacted to the antiserum against 37 kDa OMP of Edwardsiella tarda (Lane 2) and antiserum against GAPDH (Lane 3 ). The results indicated

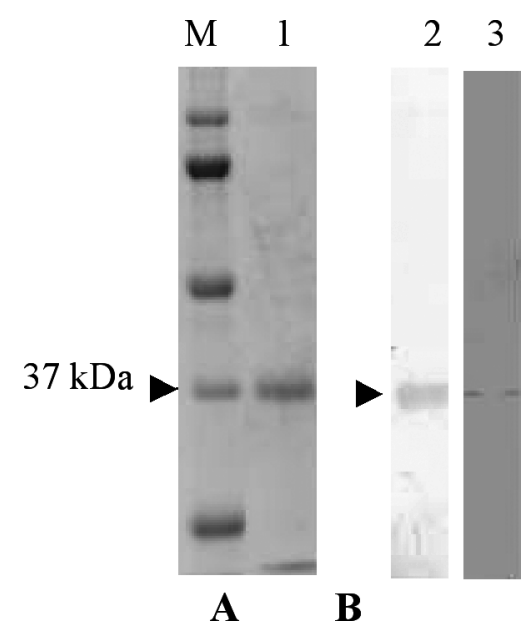

Fig. 1. Profile of $37 \mathrm{kDa}$ glyceraldehyde-3-phosphate dehydrogenase (GAPDH) in (A) SDS-PAGE gel and (B) Western blotting membrane. $\mathrm{M}$ : molecular weight marker; Lane 1: prepared GAPDH from Edwardsiella tarda; Lane 2: Western blotting using anti-37 kDa open membrane protein (OMP) of E. tarda serum; Lane 3: Western blotting using antiGAPDH serum

that the prepared protein was the E. tarda $37 \mathrm{kDa}$ GAPDH.

Fig. 2 shows the survival rate of the Japanese flounder after infection with Vibrio anguillarum strain 1122. From the second day after infection, fish in the control group started to die, and the survival rate decreased sharply until the fifth day after infection to a final survival rate of $42 \%$. The final survival rate of the immunized group was $90 \%$. Fish immunized with $37 \mathrm{kDa}$ OMP of Edwardsiella tarda maintained a markedly higher survival rate than the unimmunized fish; the 2 groups were significantly different $(p<0.005)$. This result suggested that $E$. tarda GAPDH has protective antigenicity against infection of $V$. anguillarum.

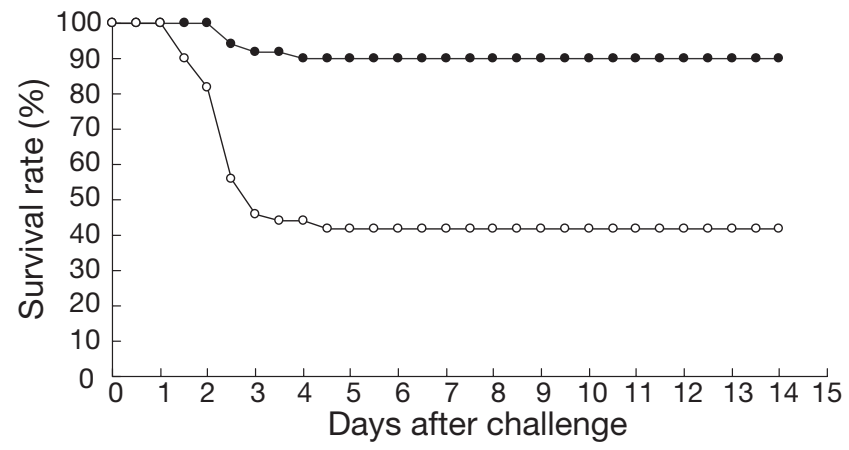

Fig. 2. Paralichthys olivaceus. Survival rate of Japanese flounder after a challenge with Vibrio anguillarum strain 1122. (•) Immunized with the $37 \mathrm{kDa}$ open membrane protein (OMP) of Edwardsiella tarda EF-1 strain; (O) control injected with phosphate-buffered saline (PBS). A significant difference between the immunized and control groups was obtained $(\mathrm{p}<0.005)$ 


\section{DISCUSSION}

GAPDH is historically recognized as a cytoplasmic enzyme in the glycolytic pathway (Dandliker \& Fox 1955, Fox \& Dandliker 1956). Recent reports, however, have revealed that GAPDH binds to the cell membrane (Tsai et al. 1982, Allen et al. 1987, Modun \& Williams 1999) and exists on the cell surface (Pancholi \& Fischetti 1992, Hughes et al. 2002). As the surface GAPDH of Streptococcus agalactiae has no N-terminal signal peptide (Hughes et al. 2002), the attaching mechanism of this protein to the cell membrane is unclear. Membrane-bound GAPDH has many functions, but the signal peptide does not have the classical function of catalyzing (Tsai et al. 1982, Allen et al. 1987, Pancholi \& Fischetti 1992, Modun \& Williams 1999, Argiro et al. 2000a). Surface-located GAPDH of Gram-positive bacteria was reported to be a highly active receptor for host proteins and effective vaccine components (Seifert et al. 2003, Bolton et al. 2004). A $37 \mathrm{kDa}$ surface GAPDH of Schistosoma mansoni is highly antigenic in the immune response of humans against schistosome infection (Argiro et al. 2000a), and further research has demonstrated that GAPDH of $S$. mansoni carries B-cell epitope and associates with antibody induction (Argiro et al. 2000b) in mice. Our previous study also showed that the $37 \mathrm{kDa}$ OMP of $E$. tarda produced antibodies in fish and protected Japanese flounder against Edwardsiella tarda infection (Kawai et al. 2004).

GAPDH is widely present in Gram-positive bacteria (Iddar et al. 2005) and is a common protein of Gramnegative bacteria (Villamon et al. 2003). Alignment of the GAPDH amino acid sequences of several Gramnegative bacteria (Escherichia coli, Salmonella enterica, Shigella flexneri, and Vibrio cholerae) showed that the sequences are highly conserved and the similarities between these bacteria are $\geq 80 \%$ (Liu et al. 2005) by using the DNA Data Bank of the Japan Homology Search System (www.ddbj.nig.ac.jp). The high conservation of the GAPDH among different pathogenic bacteria led to the idea that Edwardsiella tarda GAPDH might have protective antigenicity against other pathogenic bacteria. Thus, in the present study, Japanese flounder was immunized with the $37 \mathrm{kDa}$ GAPDH of E. tarda and was challenged with $V$. anguillarum. An encouraging result showed that the immunized fish maintained a significantly higher survival rate than the unimmunized fish. The results were obtained with a non-adjuvanted antigen; thus, an even higher level of protection with an adjuvant might be expected. Results of the present study strongly suggest that the $37 \mathrm{kDa}$ GAPDH of E. tarda may lead to the development of a multi-purpose vaccine against infection by different pathogenic bacteria.
GAPDH may be protective in several ways. The most reliable hypothesis is that immunization induces the production of antibodies in Japanese flounder (Kawai et al. 2004), which inhibits the function of the pathogen GAPDH. A similar observation was made in studies on parasites, where the use of drugs that inhibit the enzymatic activity of GAPDH decreased the survival of the infecting parasite (Callens \& Hannaert 1995, Bourguignon et al. 1997). Anti-GAPDH antibodies produced in the immunized flounder might have inhibited the GAPDH activity of the infecting Vibrio in the challenge test of the present study.

Generally, our study showed that the GAPDH of Edwardsiella tarda has protective antigenicity against infection by Vibrio anguillarum, and indicates that the GAPDH of E. tarda can be developed as a multipurpose vaccine against different pathogenic bacteria.

Acknowledgements. We thank Mr. K. Kurohara of the Prefectural Fisheries Experimental Station and fish pathology members for kindly providing experimental facilities and assistance.

\section{LITERATURE CITED}

Allen RW, Trach KA, Hoch JA (1987) Identification of the 37$\mathrm{kDa}$ protein displaying a variable interaction with the erythroid cell membrane as glyceraldehyde-3-phosphate dehydrogenase. J Biol Chem 262:649-653

Argiro L, Kohlstädt S, Henri S, Dessein H, Matabiau V, Paris P, Bourgois A, Dessein AJ (2000a) Identification of a candidate vaccine peptide on the $37 \mathrm{kDa}$ Schistosoma mansoni GAPDH. Vaccine 18:2039-2048

Argiro L, Henri S, Dessein H, Kouriba B, Dessein AJ, Bourgois A (2000b) Induction of a protection against $S$. mansoni with a MAP containing epitopes of Sm37-GAPDH and Sm10-DLC. Effect of coadsorbtion with GM-CSF on alum. Vaccine 18:2033-2038

Bolton A, Song XM, Willson P, Fontaine MC, Potter AA, Perez-Casal J (2004) Use of the surface proteins GapC and Mig of Streptococcus dysgalactiae as potential protective antigens against bovine mastitis. Can J Microbiol 50: 423-432

Bourguignon SC, Alves CR, Giovanni-De-Simone S (1997) Detrimental effect of nitric oxide on Trypanosoma cruzi and Leishmania major life cells. Acta Trop 66:109-118

Callens M, Hannaert V (1995) The rational design of trypanocidal drugs: selective inhibition of the glyceraldehyde-3-phosphate dehydrogenase in Trypanosomatidae. Ann Trop Med Parasitol 89:23-30

Dandliker WB, Fox JB (1955) Light scattering of DL-glyceraldehyde-3-phosphate dehydrogenase. J Biol Chem 214: 275-283

Fox JB, Dandliker WB (1956) A study of some of the physical properties of glyceraldehyde-3-phosphate dehydrogenase. J Biol Chem 218:53-57

Hughes MJG, Moore JC, Lane JD, Wilson R and 12 others (2002) Identification of major outer surface proteins of Streptococcus agalactiae. Infect Immun 70:1254-1259

Iddar A, Valverde F, Assobhei O, Serrano A, Soukri A (2005) Widespread occurrence of non-phosphorylating glycer- 
aldehyde-3-phosphate dehydrogenase among gram-positive bacteria. Int Microbiol 8:251-258

Kaper JB, Morris Jr JG, Levine MM (1995) Cholera. Clin Microbiol Rev 8:48-86

Kawai K, Liu Y, Ohnishi K, Oshima S (2004) A conserved $37 \mathrm{kDa}$ outer membrane protein of Edwardsiella tarda is an effective vaccine candidate. Vaccine 22:3411-3418

Kusuda R, Salati S (1993) Major bacterial disease affecting mariculture in Japan. Annu Rev Fish Dis 28:65-85

Liu Y, Oshima S, Kurohara K, Ohnishi K, Kawai K (2005) Vaccine efficacy of recombinant GAPDH of Edwardsiella tarda against edwardsiellosis. Microbiol Immunol 49: 605-612

Modun B, Williams P (1999) The staphylococcal transferrinbinding protein is a cell wall glyceraldehyde-3-phosphate dehydrogenase. Infect Immun 67:1086-1092

Pancholi V, Fischetti VA (1992) A major surface protein on group A streptococci is a glyceraldehyde-3-phosphate-

Editorial responsibility: Jo-Ann Leong,

Kaneohe, Hawaii, USA dehydrogenase with multiple binding activity. J Exp Med 176:415-426

Seifert KN, McArthur WP, Bleiweis AS, Brady LJ (2003) Characterization of group B streptococcal glyceraldehyde-3phosphate dehydrogenase: surface localization, enzymatic activity, and protein-protein interactions. Can J Microbiol 49:350-356

Suzuki S, Kuroe K, Kusuda R (1994) Characteristics of porinlike major outer membrane proteins of Listonella anguillara serotypes J-O-1, -2 and -3. Biochem Mol Biol Int 32: 605-613

Tsai IH, Murthy SNP, Steck TL (1982) Effect of red cell membrane binding on the catalytic activity of glyceraldehyde3-phosphate dehydrogenase. J Biol Chem 257:1438-1442

Villamon E, Villalba V, Nogueras MM, Tomas JM, Gozalbo D, Gil ML (2003) Glyceraldehyde-3-phosphate dehydrogenase, a glycolytic enzyme present in the periplasm of Aeromonas hydrophila. Antonie Leeuwenhoek 84:31-38

Submitted: August 8, 2005; Accepted: February 13, 2007 Proofs received from author(s): April 6, 2007 